\title{
Hubungan Aktivitas Fisik dengan Kadar Glukosa Darah Puasa pada Pasien Diabetes Melitus yang Datang ke Poli Klinik Penyakit Dalam Rumah Sakit M. Djamil Padang
}

\author{
Mala Azitha ${ }^{1}$, Dinda Aprilia ${ }^{2}$, Yose Ramda Ilhami ${ }^{3}$
}

\begin{abstract}
Abstrak
Aktivitas fisik merupakan satu dari empat pilar program penatalaksanaan diabetes mellitus. Aktivitas fisik yang kurang juga merupakan salah satu penyebab meningkatnya angka kejadian diabetes melitus. Tujuan penelitian ini adalah menentukan hubungan aktivitas fisik dengan kadar glukosa darah puasa pada pasien diabetes melitus. Jenis penelitian ini adalah analitik dengan pendekatan potong lintang terhadap 120 pasien diabetes melitus yang datang ke poliklinik penyakit dalam rumah sakit Dr. M. Jamil Padang yang memenuhi kritia inklusi dan ekslusi. Pada penelitian ini didapatkan dari 36 pasien dengan kadar glukosa darah puasa normal ada 24 pasien dengan aktivitas fisik ringan dan 12 pasien dengan aktivitas fisik sedang-berat. Dari 84 pasien yang memiliki kadar glukosa darah puasa meningkat, terdapat 60 pasien dengan aktivitas fisik ringan dan 24 pasien dengan aktivitas fisik sedang-berat. Hasil penelitian diolah dengan rumus Chi-square sehingga nilai $p=0.602(p>0.05)$. Simpulan studi ini ialah tidak terdapat hubungan yang bermakna antara aktivitas fisik dengan kadar glukosa darah puasa pada pasien diabetes melititus yang datang ke poliklinik rumah sakit M. Jamil Padang.
\end{abstract}

Kata kunci: aktivitas fisik, kadar glukosa darah puasa

\begin{abstract}
Physical activity is one of four main management for diabetes mellitus patients. Lack of physical activity can cause increasing of diabetes mellitus to happen. The objective of this study was to determine the relation between physical activity and fasting blood glucose level in diabetes mellitus patients. The methode of this research was analytic with cross sectional approach that took 120 pasients diabetes mellitus in internal medicine's policlinic Dr. M. Djamil Hospital Padang which fit the inclusion an exclusion criteria. The results were from 36 patients who had normal fasting blood glucose level there were 24 patients with mild activity and 12 with medium-heavy activity. There were 84 patients who had increase fasting blood glucose level 60 patients with mild activity and 24 patients with medium-heavy acivity. This research was processed using chi-square test and the result is $p=0.602(p>0.05)$ There is no significant correlation between physical acitivity winth fasting blood glucose level of diabetes mellitus pasients in internal medicine's policlinic M. Jamil Hospital Padang
\end{abstract}

Keywords: physical activity, fasting blood glucose level

Affiliasi penulis: 1. Prodi Kedokteran Fakultas Kedokteran Universitas Andalas Padang (FK Unand) 2, Bagian Penyakit Dalam FK Unand/RSUP Dr. M. Djamil Padang 3. Bagian Fisiologi FK Unand Korespondensi: Mala Azitha, Email : malazitha@yahoo.co.id, Telp: 081275688335

\author{
PENDAHULUAN \\ Pada tahap perkembangan Indonesia dari \\ bangsa agraris yang berkembang menuju masyarakat \\ industri telah membawa kecenderungan baru dalam \\ pola penyakit di masyarakat. Pola penyakit di \\ Indonesia saat ini mengalami pergeseran yang cukup
}


meyakinkan. Penyakit infeksi dan kekurangan gizi berangsur menurun, meskipun diakui bahwa angka penyakit infeksi masih dipertanyakan dengan timbulnya penyakit baru seperti hepatitis B, AIDS, dan angka kesakitan TBC yang masih tinggi. Disisi lain angka penyakit degeneratif ataupun non infeksi meningkat tajam, salah satu contoh adalah diabetes melitus. ${ }^{1}$

Diabetes Melitus (DM) merupakan suatu kelompok penyakit metabolik dengan karakteristik tingginya kadar gula dalam darah (hiperglikemia) yang terjadi karena kelainan sekresi insulin, kelainan kerja insulin atau gabungan keduanya. ${ }^{2}$

World Health Organization (WHO) merumuskan bahwa diabetes merupakan suatu penyakit kronis yang terjadi saat pankreas tidak dapat menghasilkan insulin yang cukup atau tubuh tidak dapat menggunakan insulin yang sudah ada. ${ }^{3}$

Indonesia merupakan salah satu dari 10 negara dengan jumlah penderita diabetes terbanyak. Indonesia menempati peringkat ke-7 pada tahun 1995 dan diprediksi akan naik menjadi peringkat ke-5 pada tahun 2025 dengan perkiraan jumlah penderita sebanyak 12,4 juta jiwa. ${ }^{4}$

Pada awalnya, resistensi insulin masih belum menyebabkan diabetes secara klinis. Pada keadaan ini, sel beta pankreas masih dapat mengkompensasi keadaan ini sehingga terjadi hiperinsulinemia dan glukosa darah masih normal atau sedikit meningkat. Setelah terjadi ketidaksanggupan sel beta pankreas, kemudian terjadi diabetes melitus yang ditandai dengan peningkatan kadar gula dalam darah yang memenuhi kriteria diagnosis diabetes mellitus. ${ }^{5}$

Latihan fisik merupakan salah satu pilar dalam pengelolaan DM yang berfungsi untuk memperbaiki sensitivitas insulin dan juga untuk menjaga kebugaran tubuh. Latihan fisik bisa membantu memasukan glukosa kedalam sel tanpa membutuhkan insulin, selain itu latihan fisik juga bisa untuk menurunkan berat badan diabetisi yang obesitas serta mencegah laju progresivitas gangguan toleransi glukosa menjadi DM. $^{6}$

Pada saat tubuh bergerak, akan terjad peningkatan kebutuhan bahan bakar tubuh oleh otot yang aktif, juga terjadi reaksi tubuh yang kompleks meliputi fungsi sirkulasi metabolisme, penglepasan dan pengaturan hormonal dan susunan saraf otonom ${ }^{7}$.

Pada keadaan istirahat, metabolisme otot hanya sedikit sekali memakai glukosa sebagai sumber bahan bakar, sedangkan saat berolahraga, glukosa dan lemak akan dijadikan sebagai bahan bakar utama. Diharapkan dengan dijadikannya glukosa sebagai bahan bakar utama, kadar glukosa darah akan menurun ${ }^{7}$.

Berdasarkan hal tersebut dan belum adanya penelitian yang meneliti tentang hubungan aktivitas fisik dengan kadar glukosa darah puasa pada pasien DM yang datang berobat ke poliklinik penyakit dalam RS M. Jamil Padang, maka perlu diteliti pengaruh aktivitas fisik dengan kadar glukosa darah puasa pada pasien diabetes melitus yang datang ke Poliklinik Penyakit Dalam rumah sakit Dr. M. Djamil Padang.

\section{METODE}

Jenis penelitian ini adalah cross sectional analitik yang dilakukan di poliklinik Penyakit Dalam rumah sakit Dr. M. Djamil Padang.

Populasi dalam penelitian ini adalah seluruh pasien DM yang datang ke poliklinik Penyakit Dalam RSUP Dr. M. Jamil Padang. Sampel pada penelitian ini adalah seluruh populasi yang memenuhi kriteria inklusi dan eksklusi, sehingga didapatkan 120 orang dengan menggunakan teknik consecutive sampling.

\section{HASIL}

Berdasarkan penelitian yang telah dilakukan, diperoleh informasi mengenai gambaran aktivitas fisik dan kadar gula darah puasa sebagai berikut.

Tabel 1. Kadar glukosa darah dan aktivitas fisik pada pasien DM

\begin{tabular}{l|c}
\hline \multicolumn{1}{c|}{ Parameter } & Jumlah (\%) \\
\hline Kadar Glukosa Darah Puasa & \\
Normal & $36(30 \%)$ \\
Meningkat & $84(70 \%)$ \\
Aktivitas Fisik & \\
Ringan & $84(70 \%)$ \\
Sedang Berat & $36(30 \%)$ \\
\hline
\end{tabular}


Berdasarkan tabel diatas terlihat bahwa kadar glukosa darah puasa dari pasien DM yang masuk kriteria normal (< $126 \mathrm{mg} / \mathrm{dl})$ yaitu sebanyak 36 orang $(30 \%)$ sedangkan pasien yang masuk kedalam kriteria kadar glukosa darah meningkat $(\geq 126 \mathrm{mg} / \mathrm{dl})$ yaitu 84 orang (70\%).

Aktivitas fisik yang merupakan salah satu dari empat pilar penatalaksanaan DM dari Tabel 1 di dapatkan jumlah sampel dengan tingkat aktivitas ringan sebanyak 84 orang $(70 \%)$ dan sampel dengan tingkat aktivitas sedang-berat sebanyak 36 orang $(30 \%)$.

Tabel 2. Hubungan aktivitas fisik dengan kadar glukosa darah puasa pada pasien DM

\begin{tabular}{|c|c|c|c|c|}
\hline \multirow[t]{2}{*}{$\begin{array}{l}\text { Aktivitas } \\
\text { Fisik }\end{array}$} & \multicolumn{2}{|c|}{$\begin{array}{l}\text { Kadar Glukosa Darah } \\
\text { Puasa }\end{array}$} & \multirow[t]{2}{*}{$\begin{array}{c}\text { Total } \\
(\%)\end{array}$} & \multirow[t]{2}{*}{$\mathbf{p}$} \\
\hline & Normal & Meningkat & & \\
\hline \multirow[t]{2}{*}{ Ringan } & 24 & 60 & 84 & \\
\hline & (28.6\%) & $(71.4 \%)$ & $(70 \%)$ & 0.602 \\
\hline Sedang- & 12 & 24 & 36 & \\
\hline Berat & (33.3\%) & (66.7\%) & $(30 \%)$ & \\
\hline
\end{tabular}

Pada Tabel 2, jumlah pasien yang melakukan aktivitas fisik ringan dengan kadar gula darah puasa normal sebanyak 24 orang (28.6\%) dan pasien dengan kadar gula darah puasa meningkat sebanyak 60 orang $(71.4 \%)$. Pasien yang melakukan aktivitas fisik sedang-berat dengan kadar gula darah puasa normal sebanyak 12 orang (33.3\%) dan pasien yang melakukan aktivitas fisik sedang-berat dengan kadar gula darah puasa meningkat 24 orang $(66.7 \%)$.

Hasil uji antara aktivitas fisik dengan kadar gula darah puasa menggunakan Chi-square diperoleh nilai $p=0.602$, yang berarti nilai $p$ lebih dari 0.05 , sehingga menurut diagnosis statistik dapat disimpulkan bahwa ativitas fisik tidak berhubungan terhadap kadar glukosa darah puasa pasien DM yang datang ke poliklinik Penyakit Dalam RSUP Dr. M. Djamil Padang.

\section{PEMBAHASAN}

Penelitian ini dilakukan terhadap 120 orang responden yang semuanya adalah pasien DM yang datang ke poliklinik Penyakit Dalam rumah sakit Dr. M. Djamil Padang. Berdasarkan Tabel 1 didapatkan bahwa kadar glukosa darah puasa dari pasien DM yang masuk kriteria normal (< $126 \mathrm{mg} / \mathrm{dl}$ ) yaitu sebanyak 36 orang (30\%) sedangkan pasien yang masuk kedalam kriteria kadar glukosa darah meningkat ( $\geq 126 \mathrm{mg} / \mathrm{dl}$ ) yaitu 84 orang $(70 \%)$. Hasil ini menunjukkan bahwa rata-rata gula darah puasa pasen DM yang datang ke poli klinik Penyakit Dalam rumah sakit Dr. M. Djamil Padang pada bulan September 2016 sampai Desember 2016 belum terkontrol. Pada kasus ini lebih kurang sepertiga pasien yang memiliki kadar gula darah puasa yang normal. Hal ini sesuai dengan penelitian yang dilakukan Rachmawati di Makasar tahun 2011 bahwa didapatkan kadar gula darah yang tidak terkontrol pada pasien DM sebanyak $71.4 \%$ sedangkan yang terkontrol sebanyak $28.6 \%{ }^{8}$

Aktivitas fisik pada pasien DM yang datang ke poliklinik Penyakit Dalam rumah sakit Dr. M. Djamil Padang bahwa jumlah sampel dengan tingkat aktivitas ringan sebanyak 84 orang (70\%) dan sampel dengan tingkat aktivitas sedang-berat sebanyak 36 orang (30\%). Hasil penelitian menunjukkan bahwa responden yang memiliki kadar glukosa darah normal maupun meningkat lebih banyak yang beraktifitas fisik ringan. Hasil ini sesuai dengan penelitian yang dilakukan oleh Rachmawati tahun 2011 di Makasar didapatkan 51 responden dari 55 responden memiliki aktivitas fisik ringan, dan sisanya aktivitas fisik sedang. Hal ini kemungkinan disebabkan karena sebagian besar mereka telah berusia lanjut, hingga tidak mampu lagi melakukan aktifitas yang agak berat. ${ }^{8}$

Aktivitas fisik yang dilakukan bila ingin mendapatkan hasil yang baik harus memenuhi syarat yaitu minimal 3 sampai 4 kali dalam seminggu serta dalam kurun waktu minimal 30 menit dalam sekali beraktivitas. Tidak harus aktivitas yang berat cukup dengan berjalan kaki di pagi hari sambil menikmati pemandangan selama 30 menit atau lebih sudah termasuk dalam kriteria aktivitas fisik yang baik. Aktivitas fisik ini harus dilakukan secara rutin agar kadar gula darah juga tetap dalam batas normal. ${ }^{9}$

Selain kemungkinan dikarenakan kebanyakan responden adalah orang dengan usia lanjut, juga ada responden yang merupakan ibu rumah tangga. Ini berkaitan dengan aktivitas yang dilakukan tidak terlalu berat dan bisa diselingi dengan istirahat. Hal ini sesuai dengan teori apabila setelah melaksanakan aktivitas fisik dilanjutkan dengan berisitirahat dalam jangka 
waktu yang cukup lama maka aktivitas fisik yang dilakukan tidak akan banyak mempengaruhi pada kadar kadar gula darah, karena pasien diabetes tidak dianjurkan untuk banyak beristirahat. Banyak beristirahat ataupun jarang bergerak akan menyebabkan penurunan sensistifitas sel pada insulin yang telah terjadi menjadi bertambah parah karena tujuan dari dilakukannya aktivitas fisik adalah utuk merangsang kembali sensitifitas dari sel terhadap insulin serta pengurangan lemak sentral dan perubahan jaringan otot. ${ }^{10}$

Uji antara aktivitas fisik dengan kadar glukosa darah puasa menggunakan Chi-square diperoleh nilai $p=0.602$ yang berarti nilai $p$ lebih dari 0.05 , sehingga menurut analisis statistik dapat disimpulkan bahwa ativitas fisik tidak berhubungan terhadap kadar glukosa darah puasa pasien DM yang datang ke poli klinik Penyakit Dalam RSUP Dr. M. Djamil Padang. Hasil ini sesuai dengan penelitian yang dilakukan oleh Fuad Hariyanto pada tahun 2013 yang melihat hubungan aktivitas fisik dengan kadar gula darah puasa pada pasien DM tipe 2 di RSU Cilegon. Dari hasil penelitian tersebut di dapatkan bahwa tidak ada hubungan antara aktivitas fisik dengan kadar gula darah pada pasien DM. ${ }^{11}$

Menurut Plotnikoff (2006) dalam Canadian Journal of Diabetes, aktivitas fisik merupakan kunci dalam pengelolaan diabetes melitus terutama sebagai pengontrol gula darah dan memperbaiki faktor resiko kardiovaskuler seperti menurunkan hiperinsulinemia, meningkatkan sesnsitifitas insulin, menurunkan lemak tubuh, serta menurunkan tekanan darah. ${ }^{12}$

Latihan fisik yang rutin menyebabkan sel akan terlatih dan lebih sensitif terhadap insulin sehingga asupan glukosa yang dibawa glukosa transporter ke dalam sel meningkat. Aktifitas fisik ini pula yang kemudian menurunkan kadar glukosa puasa pada sampel yang diperiksa. ${ }^{13}$

Anjuran untuk melakukan aktifitas fisik bagi penderita DM telah dilakukan sejak seabad yang lalu oleh seorang dokter dari China, dan manfaat kegiatan ini masih diteliti sampai sekarang. ${ }^{14}$

Intensitas melakukan aktivitas fisik akan berpengaruh kepada kadar gula darah. Intensitas ringan pada penderita DM dapat menurunkan glukosa darah, namun tidak secara signifikan ${ }^{15}$. Untuk aktivitas sedang secara signifikan dapat menurunkan glukosa darah. ${ }^{16}$ Namun lain halnya dengan intensitas berat, yang menurut Guelfi bahwa intensitas berat lebih sedikit menurunkan glukosa darah dari pada intensitas sedang. ${ }^{17} \mathrm{Hal}$ ini disebabkan oleh peningkatan jumlah hormon katekolamin dan growth hormonyang lebih besar dari pada intensitas berat, dapat meningkatkan gula darah. ${ }^{18}$

\section{SIMPULAN}

Tidak ada hubungan antara aktivitas fisik dengan kadar glukosaa darah puasa pada pasien DM yang datang ke poliklinik Penyakit Dalam RSUP Dr. M. Djamil Padang.

\section{DAFTAR PUSTAKA}

1. Suyono S. Diabetes melitus di Indonesia. Dalam: Setiati S, Alwi I, Sudoyo AW, Simadibrata M, Setiyohadi B, Syam AF, editor (penyunting). Buku ajar ilmu penyakit dalam jilid 2. Edisi ke-6. Jakarta: Interna Publishing; 2014.hlm. 2315-22.

2. Purnamasari D. Diagnosis dan klasifikasi diabetes melitus. Dalam: Setiati S, Alwi I, Sudoyo AW, Simadibrata $M$, Setiyohadi $B$, Syam $A F$, editor (penyunting). Buku ajar ilmu penyakit dalam jlilid 2. Edisi ke-6. Jakarta: Interna Publishing; 2014.hlm. 2323-27.

3. WHO. Diabetes Facts sheet (diunduh Maret 2016). Tersedia dari: http://www.who.int/mediacentre/ factsheets /fs312/en/

4. Arisman. Buku ajar ilmu gizi obesitas, diabetes melitus, dan dislipidemia. Jakarta: EGC.hIm.44-5.

5. Soegondo S. Farmakoterapi pada pengendalian glikemia diabetes melitus tipe 2. Dalam: Setiati $\mathrm{S}$, Alwi I, Sudoyo AW, Simadibrata M, Setiyohadi B, Syam AF, editor (penyunting). Buku ajar ilmu penyakit dalam jilid 2. Edisi ke-6. Jakarta: Interna Publishing; 2014.hlm. 2328-35.

6. Tjokroprawiro A, Murtiwi S. Terapi non farmakologi pada diabetes melitus. Dalam: Setiati S, Alwi I, Sudoyo AW, Simadibrata M, Setiyohadi B, Syam AF, editor (penyunting). Buku ajar ilmu penyakit dalam jilid 2. Edisi ke-6 Jakarta: Interna Publishing; 2014.hIm. 2336-46. 
7. Ilyas E. Penatalaksanaan diabetes melitus terpadu. Jakarta: Balai Penerbit Fakultas Kedokteran Universitas Indonesia; 2007.hlm.69-83.

8. Rachmawati. Pola makan dan aktivitas fisik dengan kadar gula darah penderita diabetes melitus tipe 2 rawat jalan di RSUP dr. Wahidin Sudirohusodo Makasar. Media gizi masyarakat Indonesia. 2011;1(1):3.

9. Ramadhanisa A, Larasati TA, Mayasari D. Hubungan aktivitas fisik dengan kadar HBA1C pasien diabetes melitus tipe 2 Di Laboratorium Patologi Klinik RSUD DR. H. Abdul Moeloek Bandar Lampung. Medical Journal Of Lampung University. 2013; 2(4):5.

10. Kriska A. Physical activity and the prevention of type ii (non-insulin dependent) diabetes. University of Pittsburgh. PCPFS Research DIGEST. 2010; 2(10).

11. Haryanto F. Hubungan aktifitas fisik dengan kadar gula darah puasa pada pasien diabetes melitus tipe 2 di rumah sakit umum daerah Kota Cilegon tahun 2013. E-Journal Syarif Hidayatullah. 2013; 2(2):3.

12. Plotnikoff RC. Physical activity in the management of diabetes: population-based perspectives and strategies. Canadian Journal of Diabetes. 2006; 30:52-62.
13. Tortora GJ, Derrickson B. Principles of anatomy and physiology. Edisi ke-13. Singapore: John Wiley and Sons (Asia) Pte Ltd; 2011.

14. Yunir E, Soebarji S. Terapi nonfarmakologi pada diabetes melitus. Dalam: Setiati S, Alwi I, Sudoyo AW, Simadibrata M, Setiyohadi B, Syam AF, editor (penyunting). Buku ajar ilmu penyakit dalam jilid 2. Edisi ke-6. Jakarta: Pusat Penerbitan FKUI. 2014; hlm 2336-40.

15. Fathoni A. Penurunan kadar gula darah postprandial pada latihan fisik intensitas ringan durasi 20 menit dan intensitas sedang durasi 20 menit pada penderita diabetes melitus. Airlangga University Library; 2008.

16. Henriksen EJ, editor (penyunting). Effects of acute exercise and exercise training on insulin resistance. Arizona: Department of Physiology, University of Arizona Collage of medicine. 2002; 788-96.

17. Guelfi KJ. Effect of intermittent high intensity compare with countinous moderat exercise on glukose production and utilization in individuals with type 1 diabetes. Physiol Endocrinal Metabolism. 2007:865-70.

18. Molina, Patricia E. Endocrine physiology. Edisi ke3. Louisiana USA: McGraw Hill Company. 2010; hlm:865-70. 